\title{
De la ciudad cerrada de los conventos a la ciudad abierta de los espacios públicos: Santiago $1710-1910^{1}$
}

\author{
José Rosas Vera² y Elvira Pérez Villalón ${ }^{3}$
}

\begin{abstract}
RESUMEN
El artículo analiza el proceso de formación del centro histórico de Santiago de Chile, centrándose en las manzanas y edificaciones religiosas. De este modo, se realiza una reconstrucción de la situación fundacional a partir de los primeros mapas científicos de principios del siglo XVIII y con la ayuda de textos, dibujos, grabados, pinturas y fotografías. La comprensión de la ciudad actual es inseparable de su perspectiva histórica. Cada época genera reconocibles capas espaciales y temporales. La trama urbana, que se mantiene aparentemente constante, registra diversas modificaciones en su forma y materialidad. Estas transformaciones reflejan los cambios en la organización interna de las manzanas y sus relaciones con las calles. Con frecuencia se ha generalizado que el modelo urbano del plano reticular en damero aplicado en América, ha sido una ordenación de una estricta regularidad; creemos que esta estructura se ha corporizado bajo distintas formas, registrando distinciones estructurales en aspectos de parcelación, edificación e infraestructuras viarias. Tenemos la certeza que donde se manifiestan importantes presiones de desarrollo urbano se revela la realidad de un orden, menos resistente al cambio de lo que en principio, se ha explicado en los textos y registrado en los documentos.
\end{abstract}

Palabras clave: Santiago, geografía histórica, cartografías urbanas, ciudad de los conventos.

\begin{abstract}
The paper analyzes the formation process of the historical center of Santiago, Chile, focusing on square blocks and religious buildings. Thereby, we have reconstructed the foundational state, based on the first scientific maps of the early 18th century along with the help of texts, drawings, prints, paintings, and photographs. An understanding of present day cities is inseparable from a historical perspective. Each period generates recognizable spatial and temporal layers. The urban grid, which remains apparently constant, records various transformations in its forms and nature. These transformations reflect changes in the internal organization of square blocks and their relationship to streets. It has been generally accepted that a regular and strict geometric order has been applied in the Spanish foundations of Latin America. However, this structure has been embodied in various forms, registering structural distinctions in zoning, building, and road infrastructure. We try to demonstrate that, due to urban development pressures and processes, and in spite of its historical persistence, the foundational urban grid of the Spanish Empire was less resistant to change than has been maintained in most previous literature.
\end{abstract}

Key words: Santiago, historical geography, urban cartography, city of convents.

1 Proyecto FONDECYT No 1110481. Artículo recibido el 28 de diciembre de 2011, aceptado el 30 de agosto de 2012 y corregido el 16 de octubre de 2012.
2 Escuela de Arquitectura, Pontificia Universidad Católica de Chile (Chile). E-mail: jrosasv@uc.cl

3 Escuela de Arquitectura, Pontificia Universidad Católica de Chile (Chile). E-mail: beperez@uc.cl 
Atendiendo a lo planteando por Harvey sobre los "componentes estructurales comunes de los conocimientos geográficos" (Harvey, 2007: 229) nos hemos propuesto reflexionar sobre la articulación entre las representaciones cartográficas, periodos históricos y la relación entre lugar y territorio que registra la ciudad de Santiago desde su fundación en 1541 hasta la fase de transición de la ciudad colonial a la ciudad republicana en 1830. Nos asiste la idea que la ciudad fundacional, organizada a partir de un orden de manzanas y calles ortogonales, centralizada en torno a la Plaza e Iglesia Mayor, evoluciona de lo simple a lo complejo pero dentro de un conjunto elemental de reglas. Sin lugar a dudas, este edificio y espacio público por su emplazamiento estratégico y peculiaridades morfológicas, génesis del asentamiento inicial, ha tenido trascendencia urbanística en la configuración del modelo de ciudad colonial de Santiago (Rosas y Pérez, 2010), pero al mismo tiempo, debemos advertir que es un proceso generalizado que se manifiesta junto con el desarrollo de la ciudad y a partir de otras edificaciones religiosas que configuran un tejido conventual. Utilizaremos como herramienta de investigación la representación cartográfica, que nos permite reflexionar sobre la articulación entre lugar y períodos históricos, ya que sostenemos que el conocimiento que nos entregan los mapas como fuente primaria es fundamental para la comprensión de las relaciones espaciales de un determinado territorio (Hidalgo et al., 2012).

A partir del siglo XVII los cartógrafos han comprendido el mapa como un modelo científico estándar de conocimiento, en el que su objetivo es producir una correcta representación del territorio, registrando datos reales y objetivos (Harley, 2005). Los historiadores y los geógrafos han considerado los antiguos mapas como fuentes primarias de información sobre el pasado, pues al interrogarlos ellos entregan información espacial concreta (Edney, 2005: 713). Ello es ratificado por Schlögel quien sostiene que los mapas son representaciones selectivas de la realidad (Schlögel, 2007). En este contexto, nos interesa estudiar la transformación que registra la ciudad entre 1712 y 1831, fase de transición entre la ciudad colonial y la republicana, a partir de las representaciones planimétricas realizadas en dicho arco temporal por Amadeo Frezier, Manuel de Sobreviela y Claudio Gay, y que a juicio del arquitecto René Martínez serían los planos que mayor exactitud y veracidad registran. Complementariamente, utilizaremos como referencia los mapas de Tomás Thayer Ojeda (1810) y Teófilo Mostardi-Fioretti (1864) consignados en el atlas que recopila diferentes planos y levantamientos topográficos de la capital (Martínez, 2007).

Además este trabajo se apoya fuertemente en las investigaciones que hemos realizado en los proyectos FONDECYT "La Manzana de la Catedral: la trama de la Historia" y "Una ciudad dos catedrales" ${ }^{\prime 4}$, donde hemos podido confirmar que entre el período de 1730 y 1800 no solo hay una ciudad en la cual se manifiesta un cambio estructural en la manzana, organización predial y edificio de la Iglesia Mayor, futura Catedral Metropolitana, sino que es un período que registra cambios en las manzanas conventuales y simultáneamente en la emergencia de nuevos edificios y espacios públicos.

La pregunta de investigación que surge es por tanto, cómo influye el cambio de la institucionalidad colonial basada en una lógica militar y religiosa-monárquica a una lógica estatal y republicana en la transformación y relaciones espaciales de la ciudad. Interesa la geografía histórica que registra la ciudad de Santiago con este cambio de gobernabilidad y administración ${ }^{5}$ (Harvey, 2007:230) que detona modificaciones en el trazado y configuración del manzanero fundacional y la concreción de un nuevo sistema de fronteras entre el espacio público y privado. De este modo y contrariamente a lo que con frecuencia se ha generalizado, de que el modelo ur-

\footnotetext{
4 Proyecto FONDECYT No 1090325 / 2009-2010, "La Manzana de la Catedral, la Trama de la Historia" y Proyecto FONDECYT No 1110481 / 2011-2013 "Una Ciudad, Dos Catedrales. Los cambios en el conjunto catedralicio de Santiago y el proceso de modernización urbana del último período colonial: 1730-1800"

5 Como indica Harvey: "Con su interés por la gobernabilidad, la administración, la tributación el planeamiento y el control social, el aparato estatal se ha ido estableciendo permanentemente desde el siglo XVIII en adelante como ámbito primordial para la recopilación y el análisis de información geográfica" (Harvey, 2007: 230)
} 
bano del plano reticular en damero aplicado por el Imperio español en América, ha sido una ordenación de una estricta regularidad; creemos que una indagación minuciosa del manzanero central desde las edificaciones religiosas en este período histórico y sus cartografías respectivas, permitirá revelar el hecho de que esta estructura se ha corporizado bajo distintas formas, registrando distinciones estructurales en aspectos de parcelación, edificación e infraestructuras viarias. Con respecto a esta idea, nos adscribimos a lo planteado por Fernando Aliata de que "las ciudades latinoamericanas habían sido constituidas a partir de una regularidad virtual cuya imagen visible era una cuadrícula que, como afirma Ángel Rama, operaba más allá de su existencia real" (Aliata, 2006: 59). Se tratará de explorar la evolución que ha registrado la configuración de manzanas y calles, pero sobre todo las relaciones entre arquitectura y espacialidad del conjunto urbano de la manzana de la Catedral y de otras órdenes religiosas dentro de la organización urbana general de Santiago, en un período en que la esfera pública estaba fuertemente determinada por la Iglesia y el catolicismo.

Como se sabe, la Iglesia y la organización eclesiástica estuvo vinculada con la monarquía española desde los comienzos de la colonización americana con el proceso de fundación de ciudades y reparto de tierras y solares. Ciertamente, las expediciones transoceánicas, la ocupación del territorio y el establecimiento de un sistema de ciudades, tuvo, como señala Romero, "una fundamentación jurídica y teológica" (Romero, 2004) y forma parte de una racionalización de la estructura del mundo y la expresión de una cultura.

De este modo, el descubrimiento, colonización y evangelización del territorio americano ha de ser visto, según Sloterdijk, como el comienzo real de la globalización de la tierra que se inicia en el siglo XVI (Sloterdijk, 2007). En ese marco, el sistema de ciudades establecidos en todo el continente tuvo una dimensión territorial donde la Iglesia y las diversas órdenes religiosas con sus respectivas edificaciones tuvieron un rol jerárquico, adquirieron una posición espacial relevante en la ciudad y una lógica de propiedad, parcelación y rasgos morfológicos distintos a la manzana que aplicó la modulación métrica colonial.
Ello en parte es explicativo de que el establecimiento de ciudades y la voluntad explícita de fijación de la trama ortogonal para los asentamientos en todo el continente, registrara adaptaciones según la relación con la geografía y circunstancias fundacionales. Lo que no siempre se considera es que uno de los efectos derivados del proceso de formación de la cuadrícula ha sido que el trazado de manzanas y calles son dos unidades morfológico funcionales, que en su relación público-privado, han estado en permanente fricción, y que esa relación es distinta según sean sus programas. Es decir, se trata de una explicación generalizada en los textos cuya imagen presenta una evidente discordancia con la construcción real de la ciudad. Desde esta consideración, entendemos que estamos frente a un orden, derivado del trazado ortogonal establecido en el período colonial, que no es homogéneo y que particularmente se corporiza en diversas manzanas religiosas que compiten por localización e influencia dentro de la ciudad, alterando con ello la trama y su continuidad.

Además, debemos considerar, que en la realidad, la cuadrícula presenta situaciones particulares, discontinuidades e irregularidades que evolucionan y posteriormente modifican, no solo los principios de diseño y las normas legales, sino que inciden en los patrones de urbanización en las distintas etapas de crecimiento y ocupación del territorio. Debido a esta condición de permanente tensión y movimientos registrados en las manzanas y calles, es que la forma urbana debe ser interpretada desde diferentes fuentes, integrando documentaciones escritas y planimétricas, como una manera de entender este proceso cambiante en el tiempo y en la configuración del espacio.

Se buscará probar la hipótesis de que el orden de la cuadrícula en el arco temporal de estudio ha sido inestable y se ha movido desde una configuración cerrada determinada por una trama de calles discontinuas y una lógica de manzanas residenciales constitutivas del tejido urbano y ciertas piezas con edificaciones religiosas que, en distintas localizaciones, fueron polos de desarrollo y control social, a una ciudad abierta al territorio en todas sus direcciones y configurada por espacios, edificios públicos y privados. 
De esta manera, se propone visualizar la geografía urbana e histórica de la ciudad como un permanente enfrentamiento entre espacios públicos, edificios públicos y edificaciones privadas, todo ello dentro de los estrechos márgenes de acción que permite la base espacial de manzanas y calles fijadas en un plano ortogonal.

Podríamos anticipadamente afirmar que la regularidad de la trama durante el período colonial y en su tránsito al período republicano fue un proceso lento, que evolucionó desde una condición mínima de forma cerrada a una entidad compleja y abierta, en que la trama ha estado en permanente vibración de sus límites, logrando solo una relativa estabilidad, después de un largo período de ajuste de los procesos de subdivisión predial de sus manzanas, la rectificación de las líneas de edificación y el alineamiento en el trazado de calles.

Nuestro objetivo, por lo tanto, está centrado en verificar, a través de la cartografía, los movimientos más importantes y la complejidad formal que registra el tejido urbano desde el cual se origina la ciudad, complementando el trabajo desarrollado por Armando de Ramón sobre Santiago, los tradicionales enfoques de Jorge Romero y Jorge Enrique Hardoy sobre las ciudades latinoamericanas y los novedosos planteamientos de David Harvey, Karl Schlögel y Peter Sloterdijk. No deberá sorprender entonces, que es en aquellas localizaciones, como las manzanas con iglesias y conventos, donde tenemos la certeza que se manifiestan importantes presiones de desarrollo urbano y tienen lugar distintos poderes en el tiempo se revele la realidad de un orden menos resistente al cambio de lo que se ha explicado en los textos y registrado en los documentos.

\section{Aproximación cartográfica a la ciudad de Santiago}

Debido a la pérdida de la documentación contenida en el Libro Becerro (Martínez, 2007: 24), no existen mayores antecedentes de la real forma y extensión que la planta de Santiago tuvo en sus inicios -salvo la representación realizada sobre la ciudad del siglo
XVI por Tomás Thayer Ojeda- ${ }^{6}$. Sin embargo, desde el punto de vista de la definición y constitución de las manzanas y calles de la fundación de Santiago, en febrero de 1541, podría decirse que el proyecto era más completo que lo que inicialmente debe haberse construido.

Según Romero, "la ciudad latinoamericana comenzó, la mayoría de las veces, siendo un fuerte" (Romero, 2004: 48), cuestión que reafirma el supuesto de que el plano resultante sea una trama precaria, elemental y en la que se han fijado fronteras con el entorno inmediato y territorio circundante de la cuenca de la ciudad. Santiago, desde sus inicios, operó más como un campamento militar concentrado en pocas manzanas, que como una ciudad, debido al aislamiento de la ubicación de la planta de la ciudad; zonas de control y contención requeridas, dado los frecuentes ataques. Por lo tanto, el asentamiento inicial, ha de ser visto como un lugar singular en la geografía y topografía, circunscrito a un reducido número de manzanas y calles, dentro de la cual destacan las edificaciones religiosas.

Como lo confirma Armando de Ramón, “hacia 1558 no habían aún 40 manzanas pobladas y hubo que esperar a 1580 para que la totalidad de la traza urbana designada estuviese por lo menos totalmente repartida" (De Ramón, 2000: 31). No obstante, según Romero "la ciudad desnuda de la traza originaria se pobló rápidamente de iglesias, conventos y colegios, que ocuparon una buena parte de la superficie urbana" (Romero, 2004). Santiago, a pesar de su tamaño, en el siglo XVII, como queda registrado en la planta de Ovalle, tiene una pluralidad de iglesias, numerosos monasterios de frailes y monjas, y colegios.

La lectura de las transformaciones urbanas durante los siglos XVI y XVII, a partir de sus representaciones, la hemos dejado solo restringida a una indagación conceptual de tipo analítico de los trazados en planta, ya que informan acerca del proceso inicial de

\footnotetext{
6 Como señala Martínez, el Libro Becerro se destruyó con el asalto del 11 de septiembre de 1541, donde se perdió la evidencia de la repartición de solares, el trazado y estacado de la ciudad y las edificaciones preliminares.
} 
estratificación espacial y de lo que hemos denominado la "huella genética en la evolución de la ciudad" (Rosas y Pérez, 2010).

Por ello, hemos decidido estudiar históricamente la configuración formal de Santiago desde las cartografías del siglo XVIII, concretamente a partir del documento de Amadeo Frezier de 1712, que es, según Martínez, "el primero relativamente exacto de la ciudad" (Martínez, 2007: 36-37). Con estos antecedentes y a efectos de abordar los procesos materiales de la ciudad y el manzanero central, nos hemos apoyado en diferentes textos ${ }^{7}$ y documentos, como dibujos, grabados, pinturas y fotografías; pero particularmente hemos trabajado con los planos de Armando de Ramón y las cartografías de Santiago de Chile recopiladas en el texto de René Martínez (Martínez, 2007) ${ }^{8}$ más el Plano de Santiago de 1910 realizado en el Proyecto FONDECYT $\mathrm{N}^{\circ} 1085253^{9}$.

La lectura de la ciudad es inseparable de su perspectiva histórica, pues en cada período se materializan sucesiones formales que se fijan como estratos espaciales y temporales, dando cuenta de su evolución cultural. En este sentido, podría decirse que la ciudad, a pesar de que en apariencia permanece relativamente constante, en diferentes momentos registra diversas modificaciones en su forma y materialidad, que en definitiva no son sino indicadores de cambios en la lógica y dirección de la organización interna de manzanas y calles en el tiempo.

\footnotetext{
7 Sobre la reconstrucción de las plantas de las 8 manzanas fundacionales organizadas en torno a la Plaza Mayor, más las tres manzanas que están al poniente de la manzana de la Catedral hemos utilizado diversas fuentes y nos hemos apoyado en ciertos textos, entre los cuales cabe destacar: Eduardo Secchi, Armando de Ramón, Gabriel Guarda, Eugenio Pereira Salas, Carlos Peña Otaegui y Tomás Thayer Ojeda.

8 El plano de Santiago de 1650-1700 de Armando de Ramón y el Plano de Frezier de 1714. El plano de 1790 de Armando de Ramón y el Plano de Thomas Thayer Ojeda de 1810 y el Plano de Gay de 1831. El plano de 1850-1900 de Armando de Ramón y el Plano Baedeker de 1910

9 Proyecto FONDECYT No 1085253. "Santiago 1910. Construcción planimétrica de la ciudad premoderna. Transcripciones entre el fenómeno de la ciudad física dada y la ciudad representada." Investigador Responsable: José Rosas Vera.
}

Como señala Schlögel: "cuando uno superpone varios planos de la misma ciudad tiene delante por así decir sus diferentes estratos temporales, o por ser preciso, sus representaciones. Son como abreviaturas espaciales y cartográficas del "proceso histórico" Todo está ahí: largas fases de acumulación y construcción; el barrio surgido en la fiebre de la especulación, donde no hay límites financieros o estéticos de ningún tipo; las largas fases de decadencia, retroceso, reformas y reconstrucciones, y los momentos en que barrios enteros y fábricas de las mayores proporciones se convirtieron en unos segundos en gigantescas escombreras. El plano lo fija todo: cómo era, cómo es, cómo habrá de ser." (Schlögel, 2007: 306). Además, debemos considerar, que no siempre esta estratificación es signo de continuidad de lugares, edificaciones, fragmentos o tejidos urbanos, sino por el contrario, revela desajustes y cambios en la estructura e incluso generando una importante renovación en el campo de las ideas, con consecuencias en las lógicas de los proyectos de calles y manzanas.

La importancia que metodológicamente tienen las cartografías en el estudio histórico de la forma urbana y el territorio radica en la secuencia de momentos en la formación de la ciudad. Considerando que la ciudad muta en la medida que las prácticas urbanas cambian y se desarrollan, y aunque probablemente en apariencia, ciertos signos de reconocimiento de la estructura permanezcan relativamente estables, sí se modifica la ocupación del suelo debido a: nuevos usos, ordenanzas urbanas, cambios en la propiedad y vías públicas, redefinición de fachadas, alineación de frentes y nivelación de calles, procesos de subdivisión y fusión predial, medidas edilicias de saneamiento y embellecimiento, entre otros aspectos que afectan a la morfología urbana y sus tipologías edificatorias.

Es importante observar, con minuciosidad y detalle, las distintas representaciones de la ciudad a lo largo del tiempo, puesto que forman parte de un proceso, por lo que debemos evitar ver los planos de más reciente data, como consecuencia y continuidad de otros que previamente se han realizado, sin percatarnos de los sutiles, pero significativos giros y desplazamientos que ocurren en la configuración subyacente de la ciudad. Pues 
"todo desplazamiento, toda elección topológica de la ciudad, tiene connotaciones sociales, toda definición de posición implica una toma de partido" (Gorelik, 2004: 97). De este modo, se busca encontrar una cierta correspondencia entre piezas y la convergencia de ejes o trazas entre un período y otro para justificar la idea de palimpsesto: "las diferentes formas que adopta históricamente, expresan una complejidad de relaciones formales y sucesivos procesos de transformación, así como la aparición de nuevos elementos que la enriquecen y aceleran su desarrollo urbano, confirmándonos su condición de palimpsesto" (Rosas y Pérez, 2010).

Con este trabajo se persigue una lectura de cada cartografía en una doble dimensión; por una parte, en el reconocimiento independiente de cada representación, en que cada una propicia un debate sobre la ciudad a partir de la misma autonomía y unicidad que poseen; así como por otra, en el valor secuencial y narrativo que estas tienen y que enfatizan los signos de identidad al mismo tiempo que permiten entender el desarrollo de la ciudad como un proceso continuo en la historia.

\section{Punto de partida: representaciones de Santiago fundacional}

Es posible afirmar, de los presupuestos antes indicados, que la formación urbanística y arquitectónica del manzanero de la Catedral, y la primacía de este lugar central sobre la forma de la organización urbana general, están íntimamente relacionados. El asentamiento inicial, por su emplazamiento estratégico y peculiaridades morfológicas, como hemos dicho, ha tenido trascendencia urbanística en la configuración del centro histórico de Santiago. Tres factores, a juicio nuestro, influyeron en la organización de la ciudad que se funda en 1541 y que, en estricto rigor, por diversos aspectos -entre ellos la larga crisis económica de la primera mitad del siglo XVII y el terremoto de 1647- logra consolidarse solo hacia el último cuarto de dicho siglo.

En primer lugar, la cuenca geográfica en que se asienta la ciudad y, en forma específica, el relieve que se forma al sur de la ribera del río Mapocho, al oeste del cerro Santa Lucía, inicialmente cerro Huelén y al norte de un brazo del mismo río, denominado Cañada de San Francisco, que es el territorio donde se funda el conjunto inicial de 8 manzanas en torno a la Plaza Mayor. La isla que se forma entre los dos cauces y el cerro, con pendientes suaves hacia el poniente y sur, estableció desde sus inicios límites rígidos a la planta de la ciudad, y en importante medida definió los elementos futuros de separación y contacto de la trama con el territorio circundante. Pero al mismo tiempo, esta centralidad de la iglesia y Plaza Mayor, sirvió de referencia para la ubicación de las otras órdenes religiosas dentro de la trama y en sus perímetros.

En segundo lugar, la ubicación estratégica de la malla cuadrangular en el soporte natural antes mencionado, la que, no obstante estar compuesta por un reducido conjunto de manzanas, fijó desde los inicios una relación geográfica y geométrica de continuidad de la manzana de la Catedral y la Plaza Mayor con el valle, por el ajuste del manzanero con el río y el cerro. Como hemos indicado: "Al observar el valle de Santiago podemos constatar una intención de centralidad en relación al punto originario de la capital: la Plaza Mayor, que se ubica a distancias equivalentes con respecto a los principales cordones montañosos del valle. El trazado técnico de la ciudad fija un orden, usando como referencia los puntos cardinales, el norte geográfico y la relación del manzanero con el Camino del Inca. Ello se realiza a partir del trazado del cardo, con una orientación norte sur y del decumano, orientado este oeste. Extrañamente nos encontramos frente a un trazado levemente girado en 8 grados con respecto al norte, lo que nuca una fijación de damero en relación a la orientación de ciertas preexistencias del territorio" (Rosas y Pérez, 2010). La relación del manzanero fundacional con el terreno natural, ha de verse como la fijación de un punto en que se encuentran dos ejes de escala territorial.

Finalmente, en tercer lugar, es necesario considerar el rol que la trama de iglesias y conventos tuvieron en el desarrollo del tejido urbano. En este sentido, es fundamental el papel de la Iglesia Mayor de Santiago que se inició en 1566, la que sabemos se orientaba 
hacia el norte, como aparece representada en el plano de Frezier, en el eje del cruce del río por la Cañadilla, antiguo camino del Inca y no enfrentaba a la Plaza, cuestión que ocurrió después del incendio de 1769. La importancia estratégica que por ubicación adquiere la manzana de la Catedral, a cuya edificación se anexaba el Seminario, sin lugar a dudas es consecuencia de la centralidad de la Plaza Mayor. Pero también, de una lógica geométrica derivada de una comprensión geográfica del valle del Mapocho, donde el cardo coincide con la vía que conecta al norte por el antiguo camino del Inca, y el decumano, con el paso al oriente por el portezuelo del cerro Huelén. En ambas orientaciones se ubicaban otros templos y conventos de referencia que eran elementos jerarquizadores de la trama.

Sin embargo, también hay que considerar que al momento de fundar, la construcción de iglesias, ermitas, conventos y monasterios de diversas órdenes religiosas, constituyeron elementos de control y desarrollo de la periferia y bordes de la ciudad. Estos tres factores quedan claramente registrados en la ciudad del siglo XVI y XVII, constatando la fuerte relación entre arquitectura, espacialidad y representación cartográfica. En efecto, en la visión hipotética de la fundación de Santiago de Thayer Ojeda realizado en 1905 (Figura $N^{\circ}$ 1) podemos apreciar la regularidad geométrica de la fundación en un contexto geográfico determinado por el cerro y el río. Destacan dentro de esta estructura el vacío de la Plaza Mayor y cuatro hitos religiosos señalados con una cruz.

En una ciudad de edificaciones bajas, las iglesias enmarcaban con sus torres los límites visuales y urbanos de esta primera ciudad. Podemos ver el convento e iglesia de San Francisco situado en la Cañada, en el exterior de la trama, que se enfrenta a la distancia con la parroquia de San Lázaro en el extremo opuesto, que a su vez flanqueaba y ponía límite a la ciudad en el poniente. Por el norte, el límite de la ciudad estaba dado por el convento de Santo Domingo en la calle Santiago de Azócar, hoy la actual calle Santo Domingo.

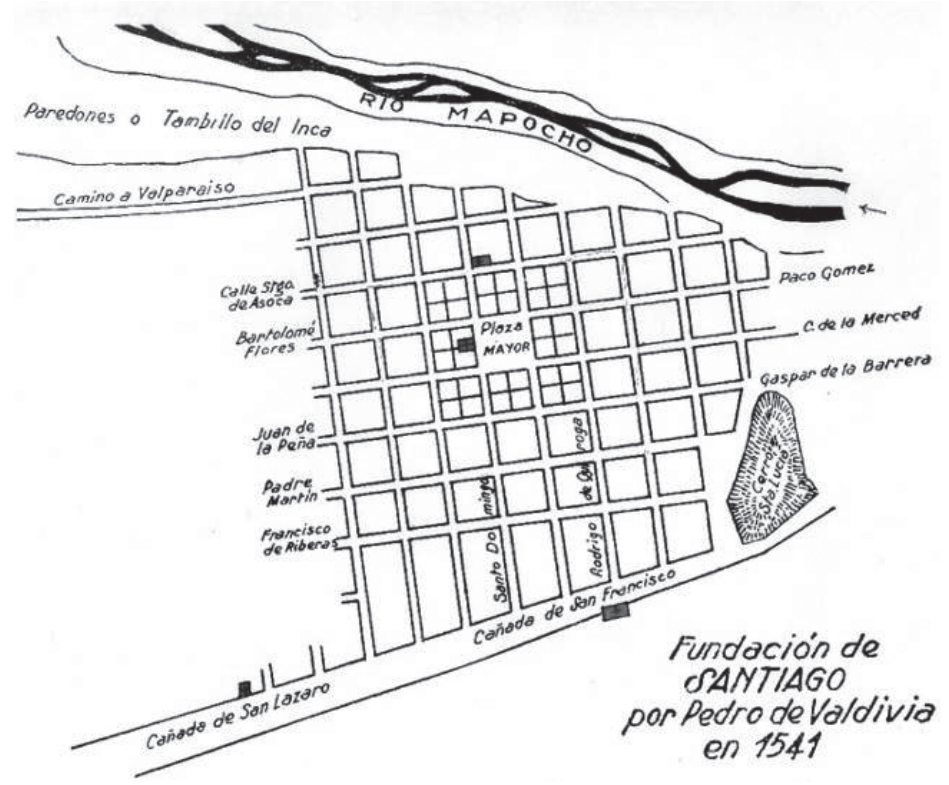

Fuente: Tomás Thayer Ojeda, 1905. 
El escenario urbano registra la aparición del convento de La Merced hacia el oriente, en el encuentro de la calle de La Merced y el vértice del cerro Santa Lucía. En las cartografías del siglo XVII se expresan con más claridad los temas que venimos tratando; en el plano anónimo existente en la Biblioteca Nacional, se visualiza la localización en el área perimetral de la ciudad de nuevos edificios religiosos, entre los que destacan: la Ermita de Nuestra Señora del Camino en el cruce de La Cañada y la calle atravesada denominada Cañada de Diego García de Cáceres, que por una parte evidencia un desplazamiento del límite de la ciudad al poniente, así como por otra, establece un borde a la extensión de la cuadrícula; y la parroquia de Santa Ana en eje con la ermita de San Lázaro, en el cruce de la actual calle Catedral y la calle atravesada que hoy se denomina San Martín.

En la segunda cartografía del siglo XVI, correspondiente al desarrollo de la ciudad desde 1552 hasta 1575, también atribuida a Tomás Thayer Ojeda (Figura $N^{\circ} 2$ ), ello se hace más evidente, probablemente por el mayor detalle de las manzanas. De una parte, la representación del río Mapocho, el ce- rro Santa Lucía y la Cañada de San Francisco con el brazo del río transformado en la acequia de Nuestra Señora del Socorro, ponen de manifiesto la incidencia de estos elementos geográficos en la regularidad de la trama y los nuevos órdenes en la manzana que derivan de estos accidentes. También queda dibujado con mayor precisión que el anterior, la formación de cuatro cuadrantes a partir del cruce de los ejes norte-sur y este-oeste originados en la escuadra sur poniente de la Plaza Mayor y en la esquina del Seminario anexo a la Catedral. Como nos indica Guarda: "Comenzaremos por dejar sentado que la existencia aquí de dos ejes principales fue de una evidencia tal que determinó su elección en 1780 como imaginarias coordenadas para dividir el plano en cuatro cuarteles y atender mejor su ornato, servicio y policía; conducentes ambos a dos importantes accesos" (Guarda, 1968: 77).

Sobre la base del plano anterior de fundación, esta cartografía retrata el proceso de construcción de una ciudad de bordes cerrados e interiores abiertos, que se va completando en base a cuartos de manzana; según el orden de propiedades asignadas ba-

Figura $\mathrm{N}^{\circ} 2$

Croquis que demuestra el desarrollo de la ciudad de Santiago desde 1552 hasta 1575

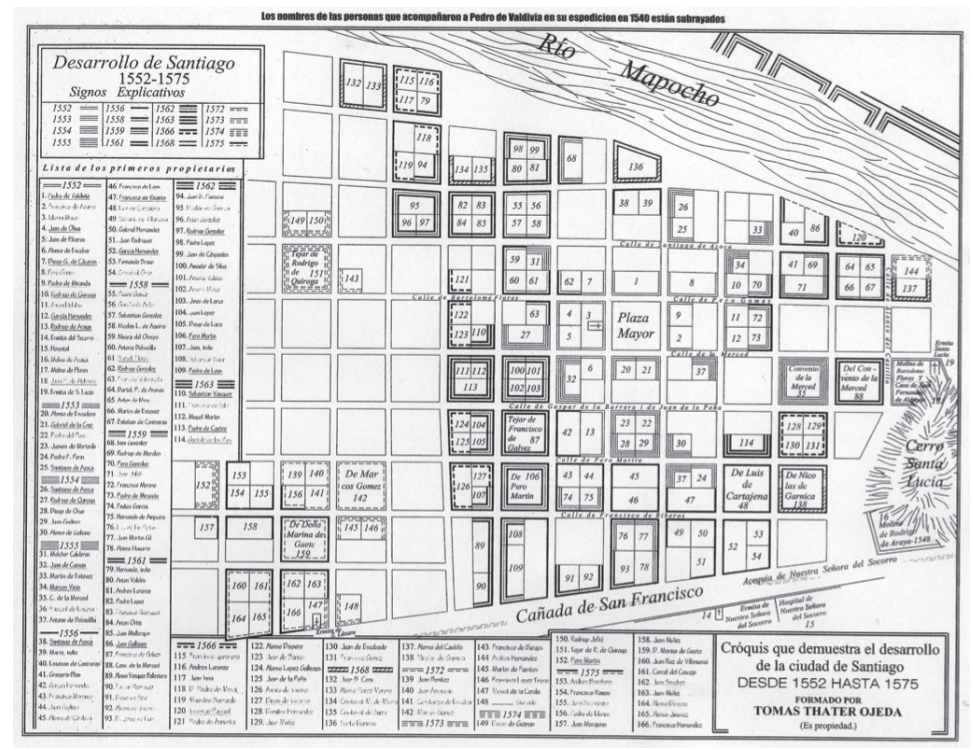

Fuente: Tomás Thayer Ojeda, 1905 (Martínez, 2007) 
sadas en los solares. El listado que aparece a la izquierda del plano refuerza el hecho que el proceso de consolidación de la ciudad se basó en una ordenada asignación de tierras a los conquistadores y a algunas órdenes religiosas según su rango de importancia, lo cual se determinaba a partir de la distancia del solar con la Plaza Mayor

En la cartografía de 1646 denominada "Prospectiva y planta de la ciudad de Santiago" de Alonso de Ovalle (Figuras $\mathrm{N}^{\circ} 3$ y $\mathrm{N}^{\circ}$ 4) vemos un esquema abstracto de la ciudad, representada de manera sintética, que podría describirse en tres tramas. La primera es la re- presentación de una regularidad estricta de la ciudad, que sabemos es exagerada y no corresponde a los hechos, especialmente cuando traspasamos los límites geográficos como el cerro, el río y la Cañada, que introdujeron deformaciones a la manzana cuadrada. Podemos suponer que esta cuadriculación del territorio constituye una hipótesis del futuro crecimiento de la ciudad. Una segunda trama tiene que ver con el tratamiento de los accidentes geográficos que están todos relacionados por la lógica de las aguas, fluyendo desde el Mapocho, pasando por el cerro Santa Lucía para terminar desviándose por la Cañada, en una visión sistémica y unitaria. Y por último,

Figura $N^{\circ} 3$

Prospectiva y Planta de la ciudad de Santiago en el siglo XVII

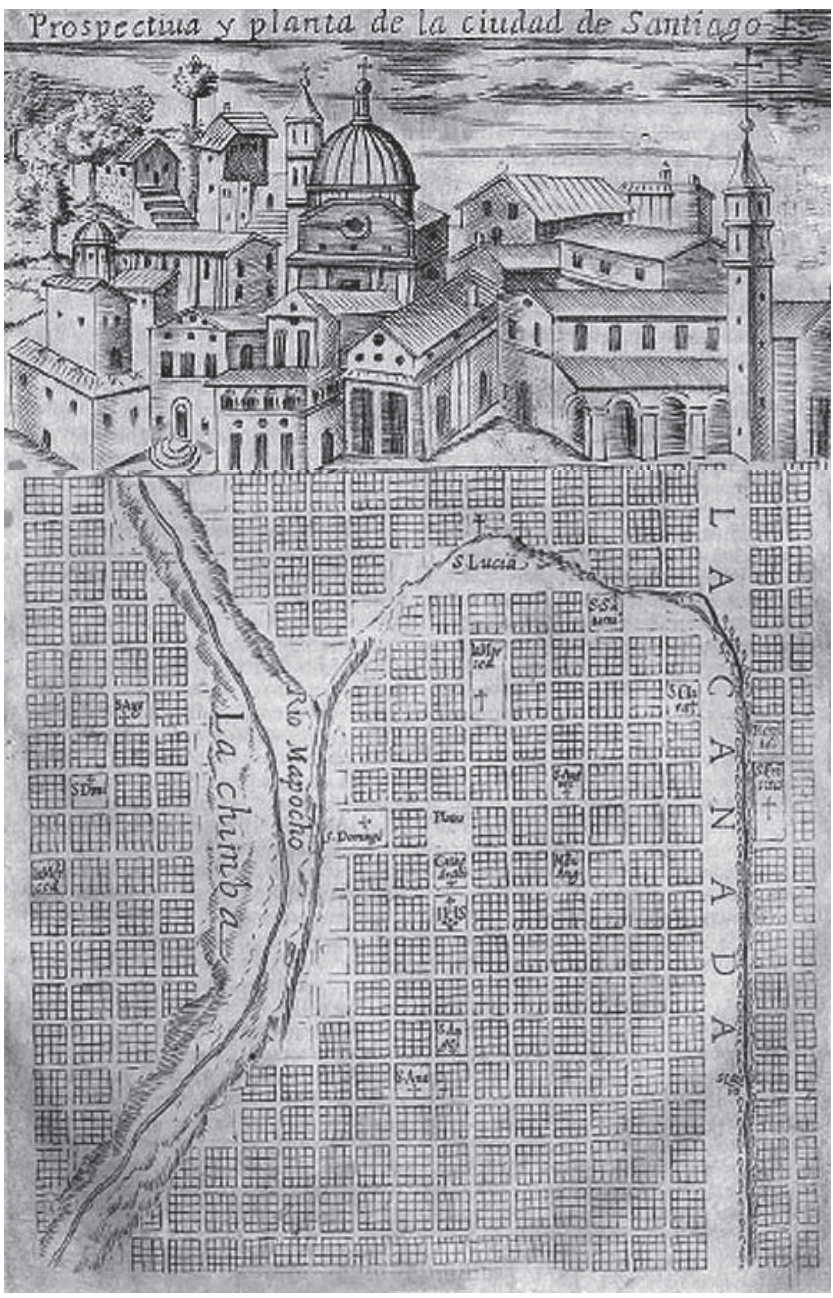

Fuente: Alonso de Ovalle 1646 (Martínez, 2007). 
aquella trama descrita a partir de los símbolos de cruz en planta que se utiliza para designar iglesias y conventos y que no necesariamente respetan el orden dimensional de la manzana cuadrada, extendiéndose más allá del módulo, y que en varios casos interrumpen la continuidad de calles del damero colonial.

En la cartografía de Ovalle, a pesar de la idealización y abstracción que la caracteriza, parece confirmarse aún más la idea de ciudad, por una parte flanqueada en la periferia de cada uno los cuatro cuadrantes que emergen del cruce de los ejes del cardo y decumano fundacional, por edificaciones religiosas, así como por otra el lugar primado que sigue teniendo la manzana de la Catedral y algunas manzanas adyacentes por acoger similares programas. En efecto, si trazamos estos dos ejes, confirmaremos que en la periferia, en el eje norte sur, la ciudad está tensada por los conventos de La Merced y San Francisco y, en el eje oriente poniente, por la ermita del Santa Lucía y la iglesia de San Ángel. Alrededor de la Plaza Mayor y la Catedral se ha consolidado la Iglesia de La Compañía, las monjas Agustinas, la Iglesia de los Agustinos y el convento de Santo Domingo. Esta cartografía además incluye una Prospectiva idealizada de la ciudad de Santiago, no obstante informa en una visión global de la ciudad de la variedad de cúpulas y torres de Iglesias que la conforman pudiendo reconocerse la Iglesia Mayor, la Compañía, Santo Domingo y San Francisco.

Las representaciones que hemos reseñado y que registran la supuesta organización física del Santiago fundacional, son claramente cartografías que expresan una fase importante en el establecimiento y consolidación de la ciudad colonial, la que toma cuerpo en el poder territorial y de dominio espacial de la Iglesia. Incluso en 1871, Benjamín Vicuña Mackenna reconoce que la ciudad durante los dos primeros siglos era un inmenso convento, "...una ciudad de tapias i una ciudad tapada...i así estaban dispuestos todos los demás edificios religiosos de la ciudad de manera que en la capital colonial del reino no podía andarse sino como en Troya, haciendo rodeos" (Vicuña Mackenna, 1872: 70). En lo que atañe a estas edificaciones, hemos de decir que eran de una cierta complejidad, en comparación a las demás edificaciones institucionales, ya que no solo ocupaban superfi- cies mayores de suelo, sino que combinaban construcciones privadas, interiores públicos, patios, huertos y recintos anexos. Coincidimos con Romero, que señala que "las construcciones religiosas imprimieron su sello a la ciudad hidalga, sin comparación posible con la arquitectura civil" (Romero, 2004).

Es así como podemos confirmar la visión de una ciudad inicial cerrada por los conventos donde las edificaciones religiosas rompen el esquema de damero original adquiriendo un "rol complejo e incluso contradictorio en el desarrollo del tejido urbano" (Valdés, 2002: 6) al ampliar sus predios pasando por alto las calles preestablecidas en la planificación fundacional.

Hasta aquí hemos intentado exponer los antecedentes cartográficos previos, donde se evidencian manifestaciones concretas de la reorganización que lentamente empieza a darse en la estructura urbana, la que transita desde una condición inicial elemental hacia una mayor complejidad formal y heterogeneidad del manzanero.

\section{Tensiones y cambios en la regularidad de la trama de la ciudad: desplazamientos de fronteras y límites vibrantes en el orden de la cuadrícula de Santiago}

Podríamos afirmar que el período entre 1541 y 1710 constituye un primer momento en la evolución de la ciudad, caracterizado por un proceso de desarrollo lento y paulatino de manzanas residenciales que coexisten con edificaciones con programas de culto, atracción de fieles, prácticas religiosas y lugares de retiro, que actuaban como piezas distintivas en las unidades de relleno a las que estaban adscritas. Como señala Peña Otaegui: "A medida que se iba normalizando la vida de sus pobladores, crecía el número de las iglesias, capillas y conventos" (Peña Otaegui, 1944: 33). En este escenario urbano intensificado por la presencia de diversas órdenes religiosas, surgen relaciones nuevas en el orden de la cuadrícula, precisamente por 
los desplazamientos del poder eclesiástico en el espacio.

Entra en juego así, hacia comienzos del siglo XVIII, un orden y una espacialidad trazada a partir de la tridimensionalidad de las torres y campanarios de las iglesias, las que actuaban como hitos desde la distancia, en contraposición a una ciudad de edificaciones bajas y manzanas cerradas. Pero las iglesias y conventos serán también lugares de encuentro; edificaciones en torno a los cuales girará la vida urbana y las prácticas sociales, surgiendo así, una trama de sitios de intercambio entre los exteriores públicos de la calle y/o plazoletas y los espacios públicos de los interiores de las naves.

Cabe señalar que los monasterios se fijan y orientan en el mismo sentido antes indicado para las iglesias, como edificaciones que no solo otorgan identidad a las manzanas y calles en que se localizan, sino que emergen como espacios de la ciudad que complejizan la estructura urbana, en una primera fase en la parte central y posteriormente, en las periferias como elementos de desarrollo urbano.

Como veremos, la ciudad de Santiago -en este proceso de secularización que cambia la constitución de las manzanas- evoluciona desde una organización formada por un manzanero central denso y la adición de piezas que se ordenan en el resto de unidades de relleno según las reglas del damero, a una estructura constituida por distintas piezas, trazas y tejidos urbanos que no son, sino, la clara manifestación de nuevas centralidades y al mismo tiempo nuevos límites y tensiones en el espacio.

Este cambio de fisonomía queda documentado en el plano realizado por el ingeniero Frezier (Figura $\mathrm{N}^{\circ} 4$ ) y probablemente el primer plano de Santiago dibujado con instrumentos y mayor precisión técnica. El plano idealiza el trazado regular y homogéneo concentrado en la parte central pero es muy claro en la representación del sistema de acequias y canales. Además representa el crecimiento extramuros de la ciudad en el sector de La Chimba en la ribera norte del río Mapocho, como continuidad de la trama central y en la parte sur de La Cañada. Hacia el oriente el cerro Santa Lucía se mantiene como una barrera en la expansión de la ciudad y, hacia el occidente, la ciudad ha crecido solo unas pocas manzanas más, del límite que tenía en períodos previos.

De la lectura del plano, lo que ya se puede apreciar, es la condición de límite excepcional de La Cañada, en cuya longitud se ubican una serie de elementos singulares que configuran el borde de la ciudad. Destaca en primer lugar, el convento de San Francisco, que parece ser la pieza de mayor envergadura en la ciudad, representado como un gran volumen negro, que acentúa la condición de remate de la calle de San Antonio y su posición de asomo sobre la Cañada. En ese movimiento de retranqueo que muestra la Iglesia de San Francisco, conviene observar detalladamente la macromanzana del convento en la escala de la planta de La Cañada. Desde la lógica geométrica del trazado, podríamos decir que -precisamente por ser desde los inicios un curso de agua que deriva del río Mapocho, y en consecuencia una vía de borde- se diferencia morfológicamente del orden de calles de la cuadrícula que en completitud se desarrolla al norte, estableciendo al mismo tiempo una diferenciación de los tejidos urbanos que ya se esbozan hacia el sur.

En el plano de Frezier, La Cañada está representada como una explanada de suelo, en que el cauce de agua superficial por gravedad y pendiente -desde el giro que adquiere en el cerro Santa Lucía- impone una anchura variable y bordes asimétricos a la disposición formal de esta zona fronteriza. No obstante, la elementalidad y rusticidad de esta explanada de suelo y acequia -que hacia 1831 tendrá la fisonomía de un paseo, denominado Alameda de las Delicias- ya en esta planta registra una sucesión de edificios emblemáticos en línea, soldados al manzanero que actúa como borde. En la Cañada occidental están la Ermita de San Lázaro, el noviciado de las Agustinas y la Capilla de San Miguel en el costado norte; y el noviciado de los jesuitas hacia el sur. En la Cañada oriental, aparte del cerro Santa Lucía y la Ermita de San Saturnino, se distingue el monasterio de Santa Clara de la Cañada, y como contrapunto al sur, el edificio de Las Carmelitas, y San Juan de Dios.

Vinculamos este desarrollo que registra la planta de la ciudad de Frezier -en compara- 
Figura $\mathrm{N}^{\circ} 4$

Plano de Santiago

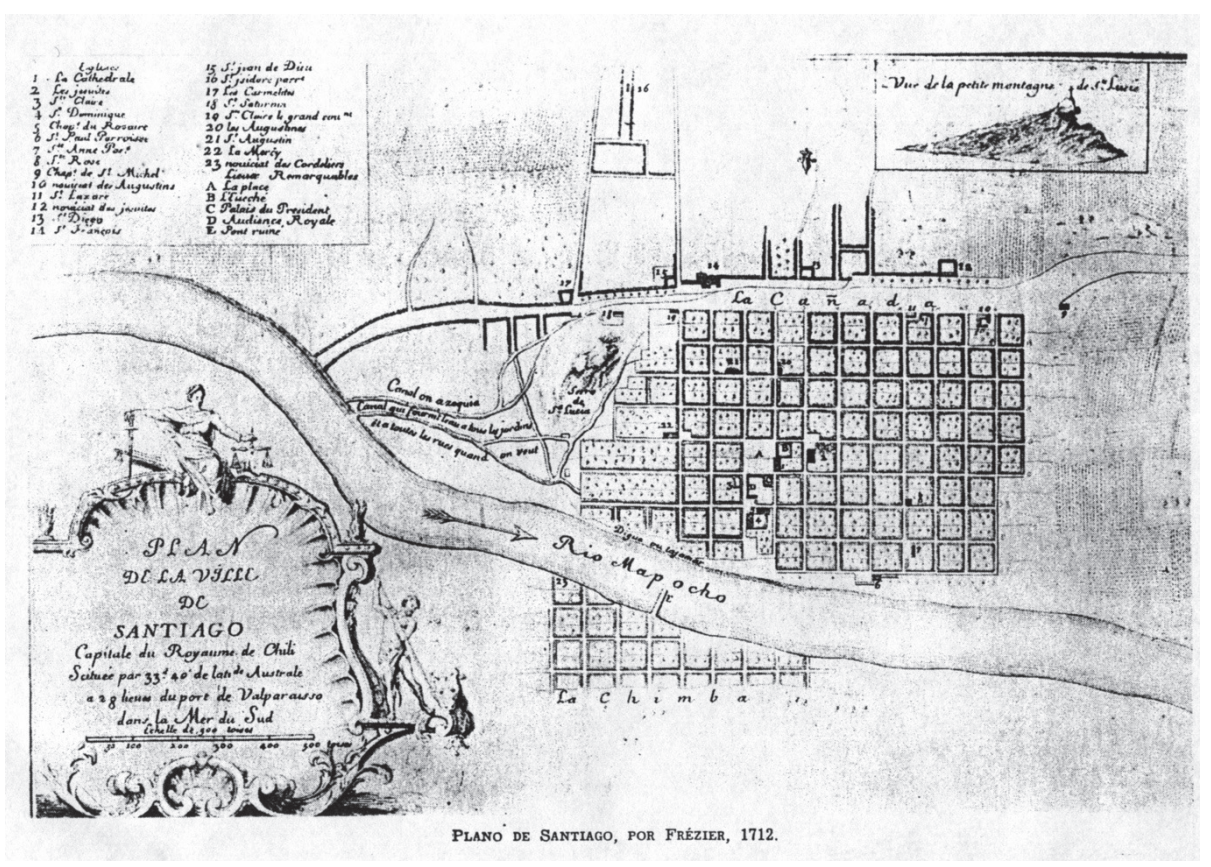

Fuente: Frézier 1712 (Martínez, 2007).

ción a anteriores cartografías- a la llamada "refundación de Santiago" a la que alude De Ramón, la que según el historiador, deriva del impulso que adquiere la ciudad hacia el último cuarto del siglo XVII, en que por medio de impuestos para obras públicas, se intenta superar los efectos de la crisis militar y económica, y entre ellos el terremoto de 1647. En efecto, cuando se refiere a la refundación de Santiago sosteniendo que el "aspecto que presentaba hacia los últimos años del siglo XVII y los diez primeros del siglo siguiente, cuando la reconstrucción estuvo completamente terminada" (De Ramón, 2000: 67), sabemos que se apoya en las menciones sobre la ciudad que detalla Frezier. Estas, de alguna manera, quedan documentadas en el Plano de 1712 donde el orden de la cuadrícula es una planta ortogonal, compuesta en una alta proporción por manzanas cuadradas con casas o edificaciones cerradas al exterior y en cuyo interior, el sistema de canales atraviesa los patios y huertos, las que conviven con 23 instituciones eclesiásticas distribuidas en toda la ciudad.

La configuración de estas edificaciones, convergen hacia comienzos del siglo XVIII a la consolidación de las manzanas y calles e incidirán en la organización espacial cerrada que registra la ciudad durante casi todo el siglo. De hecho, en el plano realizado por el fraile franciscano Manuel de Sobreviela (Figura $N^{\circ} 5$ ), ochenta años después, se indica que la ciudad de Santiago ha disuelto la condición de ciudad fuerte y se observa una extensión de la modulación métrica colonial a una superficie mayor del territorio. Claramente la ciudad se ha extendido, formalizando los espacios públicos de La Cañada y el borde del Mapocho, y ha emergido el sector adyacente al cerro Santa Lucía como parte de la ciudad, mientras los sectores rurales inmediatos forman parte de la ciudad, son extensiones o gradientes de la urbanización central. Destaca el poniente de la ciudad, que ha crecido en extensión e incorporado el canal de regadío de la actual avenida Brasil. Al norte se indican grandes sitios conventuales que coexisten con predios agrícolas. También la ciudad ha crecido al oriente y se ha materializado el encuentro de La Cañada y el camino de Vitacura con los Tajamares. En la cartografía se distingue claramente el desarro- 


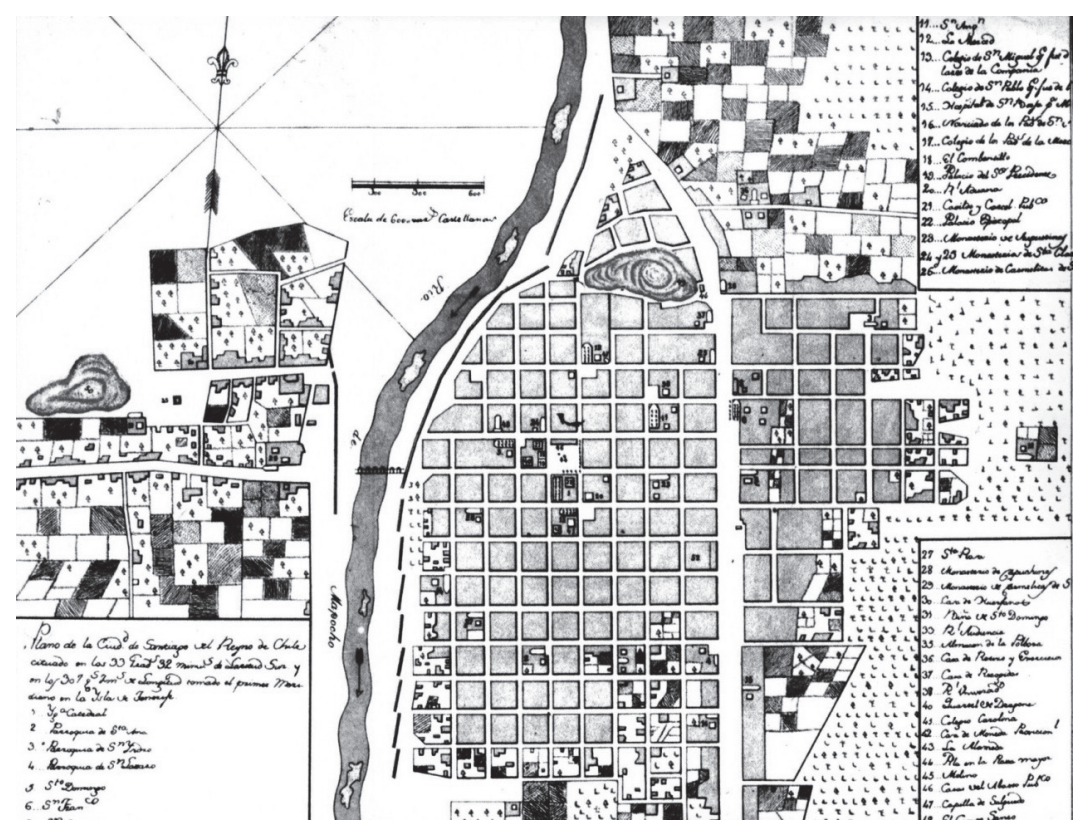

Fuente: Reproducción de original existente en el Museo Británico (Martínez, 2007)

Ilo de numerosas edificaciones religiosas que cubren toda el área urbana.

Debemos comprender esta situación como parte de un proceso más global de secularización de la ciudad, descrita por Sol Serrano, de un Santiago profundamente religioso, configurado territorialmente por conventos, monasterios e iglesias (Serrano, 2008). Esta institucionalidad crece, hasta que a inicios del siglo XIX comienzan los primeros choques con las políticas estatales laicas, cuestión que se manifestará en la estructura urbana. Como se sabe, a fines del siglo XIX muchos conventos fundados en los orígenes de la ciudad, como las Agustinas y Clarisas, debieron trasladarse del centro según indicaciones del intendente Vicuña Mackenna, por encontrarse en una ubicación demasiado estratégica en el trapecio fundacional, donde se requería la apertura de calles para lograr la continuidad de la trama, obstruida por edificaciones y predios conventuales.

En lo que respecta al proceso de desarrollo registrado a partir de la Independencia y formación de la República, trabajaremos con el Plano de Thomas Thayer Ojeda de 1810 (Figura № 6) y el Plano de Claudio Gay de 1831 (Figura $N^{\circ}$ 7). Entre ambos planos median apenas dos décadas, y no obstante ser dos maneras de representar la ciudad en tiempos distintos, prácticamente en lo referido a la figura y rasgos más característicos, son muy similares. Corroborando lo anterior, el plano de 1831, está grabado por Erhard y tiene colores y texturas que representan diferenciadamente la espacialidad de las manzanas y partes construidas $y$, el contenido de estas, que expresan los usos del suelo urbano y rústico.

El plano de 1810 representa más la estructura de manzanas y calles, sin mayores definiciones, a la sola salvedad de la notación de algunos edificios singulares. Esta representación en negro, viene a confirmar la coexistencia de edificios significativos y la trama de conventos e iglesias, pero también señala el desplazamiento de la centralidad a otros lugares.

En términos de los límites entre la ciudad y el campo -si se superpusieran ambos pla- 
Figura $\mathrm{N}^{\circ} 6$

Desarrollo de la ciudad en 1810

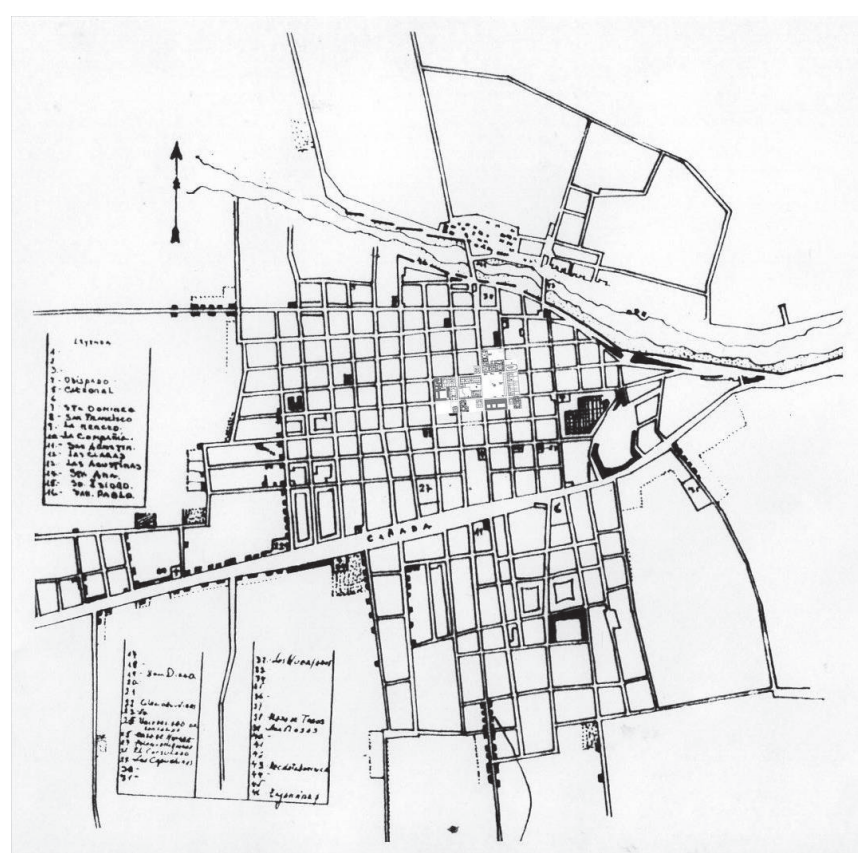

Fuente: Elaboración propia sobre Plano de Santiago 1810 formado por Tomás Thayer Ojeda, 1941 (Martínez, 2007).

nos (1810-1830) - sus perímetros en planta serían bastante coincidentes. Podríamos afirmar que no hay cambios mayores en la fisonomía de la organización urbana, pero lo que sí queda sumamente claro, es que el orden de la cuadrícula no es un constructo unitario y más bien lo que prima es la lógica de lo heterogéneo y un crecimiento que no sigue una secuencia lógica .

En efecto, la existencia de manzanas que no se rigen por las dimensiones originales de 138 varas de lado (115 m aproximadamente) obstaculizan la continuidad de la grilla de vías, que justamente por eso eran denominadas genéricamente como "calles tapadas". En tanto la planta ortogonal no esté regularizada, cuestión que ocurre tardíamente hacia 1893 -como queda testimoniado en el Plano de Santiago trabajado para la Guía de toda la República realizado por Aníbal Labarca Feliú- no podríamos hablar de estabilización de la trama.

En ambas cartografías, la ciudad se ha expandido más allá de las fronteras que los ac- cidentes geográficos -como el río Mapocho, el cerro Santa Lucía y el brazo menor del ríoestablecían como umbrales de desarrollo. Así pues, puede observarse un contrapunto entre el sector central y las nuevas periferias que se agregan y la transformación de arrabales en barrios. De acuerdo con esto, es necesario destacar la existencia de dos puentes, que permitían la comunicación norte sur entre las dos riberas del Mapocho, generando un efecto sobre las relaciones espaciales: el primero al permitir la continuidad de las calles San Diego, Ahumada, Puente y Cañadilla (antiguo Camino del Inca y actual Avenida Independencia) y el segundo, más hacia el oriente, a través del cual se establece una conexión con las calles de Santa Rosa, de las Monjas Claras, de la Merced y la calle de la Recoleta.

Junto a la existencia de estos puentes, la presencia de dos iglesias flanqueando el acceso a la Cañadilla y a la Calle de la Recoleta, en La Chimba, situada en la ribera norte del río Mapocho, nos indica la construcción de equipamientos de servicio religioso ubicadas en la periferia. La ciudad en este período, 
Figura $\mathrm{N}^{\circ} 7$

Desarrollo de la ciudad en 1831

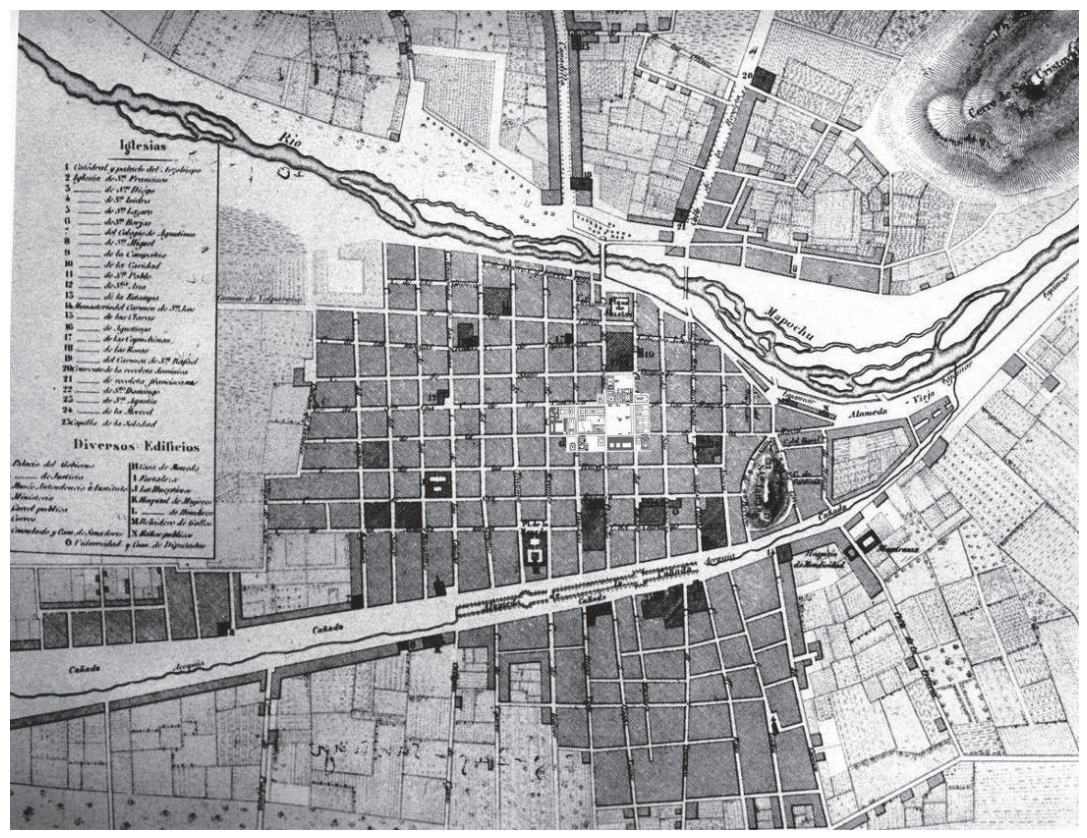

Fuente: Elaboración propia sobre el Plano de Claudio Gay de 1831 (Martínez, 2007).

respecto al anterior, ha crecido en todas las direcciones y en cierta medida, se han podido conectar a la parte central, con sectores, otrora considerados extramuros. Hacia el oriente, se ha traspasado el cerro Santa Lucía, cuestión que ha sido posible por la construcción de los Tajamares del río, cuyas obras permiten reducir la curva que se produce en el giro desde el nororiente al norponiente, y contener las aguas que por la amplitud del cauce en esa zona, se desviaban como acequias o canales hacia La Cañada.

Hacia el sur, se ha traspasado la frontera denominada ultra Cañada, constituida por la chacra Cudupaya y la Ollería -entre otros paños agrícolas- que se transforman en barrios a partir de las subdivisiones prediales hechas por los dueños de estos suelos rústicos. Parte de la especificidad de este sector -como hemos ya mencionado- deriva de la condición de frontera que tiene este lado sur de la ciudad. Este sector se caracteriza, por una parte, por la coexistencia de edificios significativos y manzanas compactas que enfrentan longitudinalmente la explanada de La Cañada, en parte convertida ahora en Ala- meda, así como por otra, por la deformación geométrica y la discontinuidad que registran las conexiones transversales entre este sector y la parte central. Como señala Waldo Vila al referirse a la extensión del crecimiento de la ciudad hacia el sur "la ruptura que se da con la cuadrícula, definida desde la fundación de la ciudad en 1542, modificando el patrón de manzanas cuadradas otorgado por el casco histórico de la ciudad. De esta forma, se pasa a una planta basada en la retícula, con un tipo de manzana rectangular, que va copando los espacios agrícolas que componen el cinturón de Santiago. Así, se puede observar la descomposición del damero colonial como uno de los elementos más importantes de las fuerzas centrífugas de expansión urbana" (Vila, 2010).

Hacia el poniente el crecimiento de la ciudad está fijado por el canal de Negrete, denominado en otra época, Cañada de García de Cáceres, y registra un desarrollo lineal de la propia Cañada y del camino a Valparaíso por la prolongación de San Pablo. Por lo tanto se trata de actuaciones que ratifican una progresiva ocupación del territorio y el des- 
plazamiento paulatino de fronteras que detenían el crecimiento de la ciudad. Estos límites se disuelven a través de sectores que se unen junto con la emergencia de nuevos tejidos urbanos en la periferia. Al mismo tiempo que crece y se densifica la trama en la parte central. Cartografías como la de Castagnola de 1854, y especialmente las de Mostardi- Fioretti de 1864 (Figura $N^{\circ}$ 8) y la de Ansart de 1875 , entre otras, no hacen sino confirmar la fase de transición de la ciudad y el abandono definitivo de la ciudad de los conventos que se registraba.

El Plano de Mostardi Fioretti puede ser visto como la culminación de los mapas concebidos como representaciones fisiognómicas, mientras que el de Ansart como la emergencia de un mapa entendido como instrumento de planificación. Ambos planos presentan una similar superficie de ocupación en el territorio, que en estricto rigor corresponde a la expansión urbana del siglo XIX, aunque el de Mostardi Fioretti está centrado en la representación de los hechos y el de Ansart, en combinar la realidad existente con la proyección de eventos futuros (Pérez y Rosas, 2011).

El análisis detallado de estos materiales de la ciudad ha posibilitado visualizar, al corto período de tiempo que media entre ambas cartografías, como un período de transición a la modernidad. En este marco, el Plano de Ansart y el Plan de Transformación de Santiago de Vicuña Mackenna constituyen dos documentos que confirman esta afirmación, tanto por representar el escenario donde se manifiesta la experiencia moderna, como por indicar una seria preocupación por los desequilibrios sociales y espaciales que allí acaecían, así como proponer correcciones y normas para su resolución, cuestión que empezará a reflejarse en los planos sucesivos que se realizan desde el plano de Boloña de 1895 al Plano Baedeker de 1910.

Pero seguramente la ciudad de 1910 (Figura $\mathrm{N}^{\circ}$ 9) será la manifestación más representativa de lo que estamos planteando y el

Figura $\mathrm{N}^{\circ} 8$

Santiago en 1864

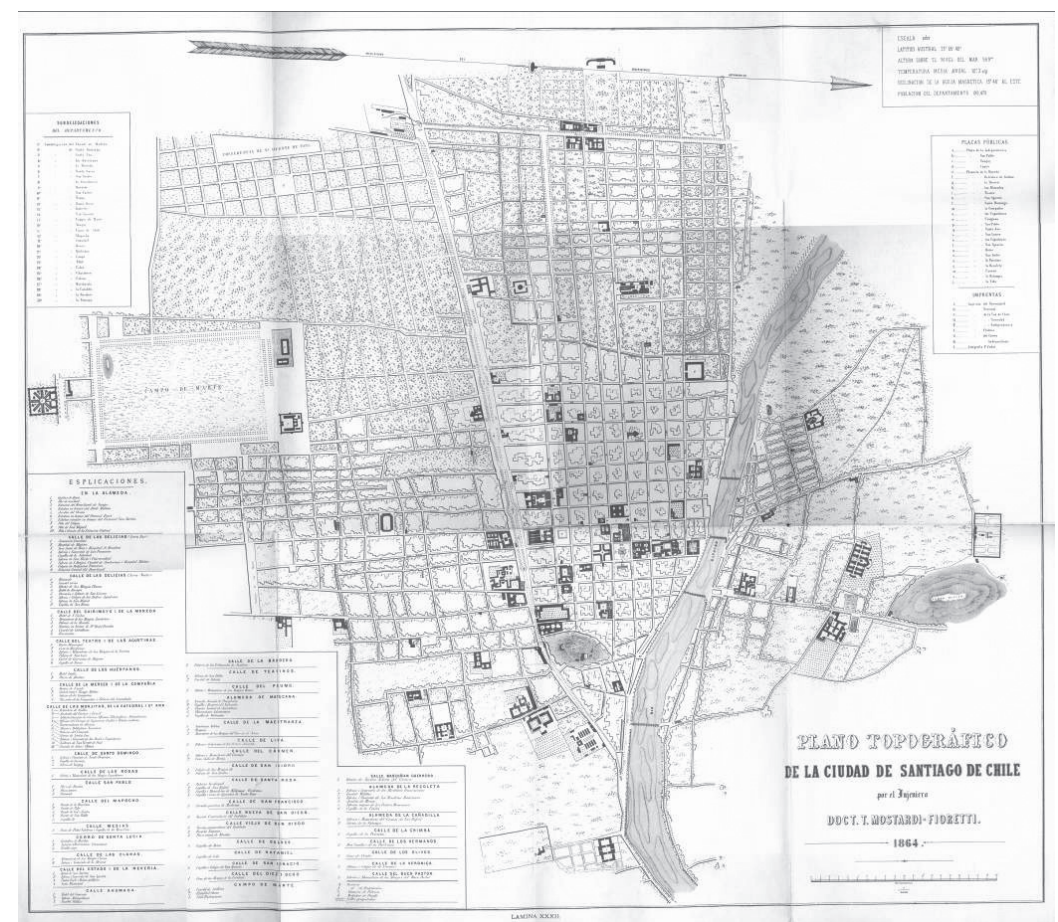

Fuente: Plano de Santiago de Mostardi-Fioretti 1864 (Martínez, 2007). 
impulso definitivo para que se generen nuevos barrios, espacios públicos y la cristalización, en la parte central de la ciudad, de nuevas centralidades que coexisten con el centro histórico fundacional localizado en torno a la Plaza de Armas. Como se observa en el plano, la ciudad en esa fecha, coincide prácticamente con los límites de lo que es hoy la comuna de Santiago. Lo que confirma a este territorio como la estructura urbana de mayor centralidad histórica, simbólica, terciaria, política y el área de mayor identidad en el imaginario urbano nacional. La estructura urbana registra un alto porcentaje de las manzanas con una fuerte lógica de división y subdivisión predial derivada de la ocupación del suelo con tipologías de casas patio y conventillos o conjuntos residenciales con pasajes. También se registran viviendas de lujo, como palacios o casas quintas, que igualmente siguen las directrices de subdivisión ortogonal de un frente o dos a la calle y de patios y subpatios hacia el interior.

La estructura de calles y avenidas siguen el patrón ortogonal de la cuadrícula fundacional, y todo el conjunto queda delimitado por el sistema de movilidad ferroviaria, que es consecuencia del Camino de Cintura propuesto por Vicuña Mackenna en 1875. No obstante ello, y como se observa también, la estructura urbana comienza a registrar operaciones de arquitectura pública y privada que modifican la trama, por inclusión de retiros y antejardines, así como edificios que no se adscriben totalmente a la unidad de relleno de la manzana: "Es así como hacia 1910 se consolida una nueva espacialidad urbana, a saber: la trama deja de ser la modalidad de ordenación de calles y manzanas, ante la irrupción y desarrollo de programas, usos, y artefactos de diferentes escalas derivados de

Figura $\mathrm{N}^{\circ} 9$

Santiago en 1910

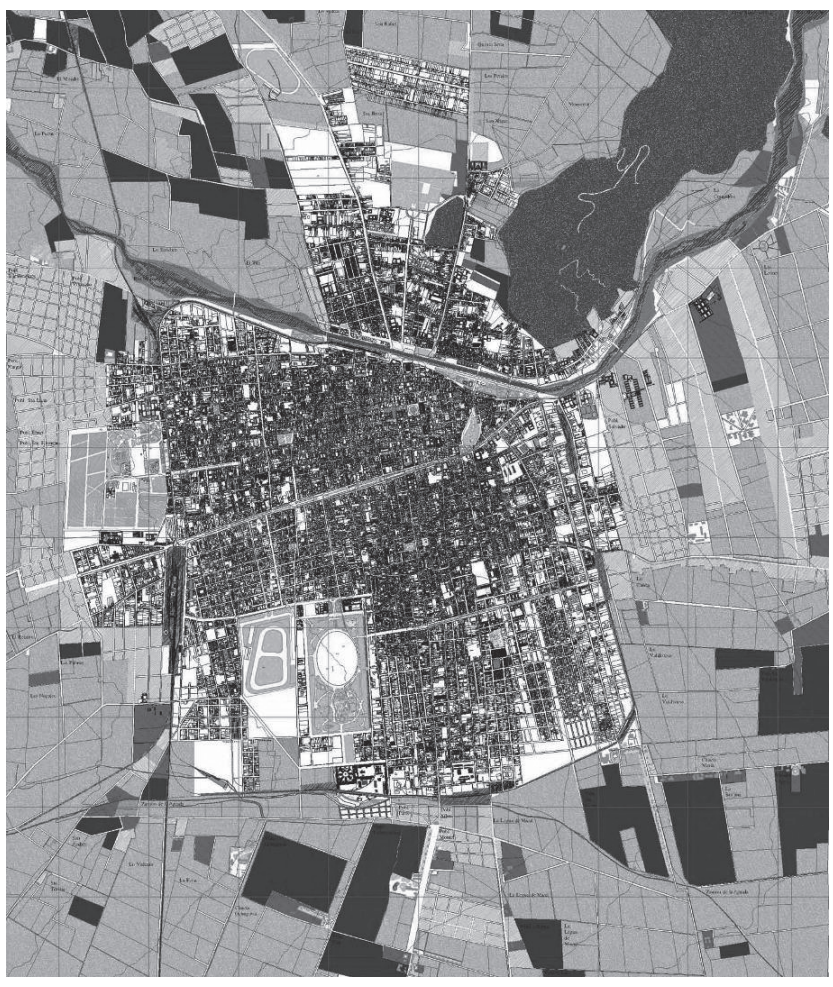

Fuente: Proyecto Fondecyt №1085253. "Santiago 1910. Construcción planimétrica de la ciudad premoderna. Transcripciones entre el fenómeno de la ciudad física dada y la ciudad representada." 
la industrialización" (Rosas y Pérez, 2010). Los espacios públicos y la proporción de estos en relación al área construida es alta, destacando una importante red de estas piezas, vinculadas a avenidas, paseos, plazas y parques, que se combinan con equipamientos de cines y teatros que al período son bastantes y donde también se evidencian las infraestructuras hospitalarias y educacionales, cuya disposición y localización es muy coherente con la cantidad de población residente y con los diferentes distritos y barrios que coexisten al interior.

Los barrios más emblemáticos eran Brasil, Portales, República, España y Dieciocho. Una buena proporción de estos convivían con sectores residenciales de menores ingresos. Sin embargo, había sectores pobres, generalmente localizados hacia los límites del anillo de circunvalación, donde se localizaban los mataderos e industrias: "como nos muestra este plano de 1910, ya se puede observar la fisonomía que comienza a tomar gran parte de la zona sur de Santiago, en base a la influencia desarrollada por el área del Matadero, en especial la extensión de su forma urbana a los terrenos ubicados entre la calle San Diego y el costado oriente del parque Cousiño, definiendo una área residencial, con diversos tipos de urbanizaciones, pero que responden a un esfuerzo por establecer la cuadrícula como una base para su desarrollo" (Vila, 2010: 10). El barrio Yungay y los barrios de San Diego son ilustrativos de ello. Hay que remarcar eso sí, que el sistema de ferrocarriles y tranvías permitía una alta movilidad interna, generando una alta accesibilidad de la población a los diferentes programas de la ciudad y la emergencia de una arquitectura pública monumental que celebra la República.

El urbanismo era una condición a la arquitectura y ambas dimensiones estaban articuladas a través de operaciones de paisaje, ingeniería y planificación urbana y territorial: "esta nueva forma de generar orden urbano se diferenciaba notablemente de experiencias anteriores, como el parque Cousiño e incluso la Quinta Normal que, al momento de integrarse a la ciudad, lo hacían desde extramuros" (Rosas y Pérez, 2010). Por lo tanto, es posible afirmar que esta ciudad es el cimiento de la actual metrópolis de Santiago, y que estas arquitecturas, espacios públicos, infraes- tructuras viarias y redes de servicio, paisajismo y ocupación del territorio han iluminado e incubado los desarrollos contemporáneos.

\section{Conclusiones}

Estamos, de alguna manera, confirmando que la cultura urbana desarrollada en el período colonial, está directamente relacionada con la religión y las instituciones religiosas y que, como señala Vargas Llosa, "cultura y religión, no siendo la misma cosa, son inseparables" (Vargas Llosa, 2012.). La ciudad colonial, como hemos presentado, tuvo durante un largo período de tiempo, un desarrollo urbano y territorial fuertemente determinado por la religión y la evangelización de la cultura, configurando así un sesgo específico a la morfología urbana y las tipologías edificatorias e impregnando la vida cotidiana y la esfera pública. En ese contexto, cuando se produce un cambio institucional, como el que se detona con la secularización del Estado en el siglo XIX, consecuencia de un nuevo sistema político en un país como Chile de origen católico, cabe reconocer también un cambio en la forma y estilo de vida en la ciudad. La variedad de localizaciones que la Iglesia tiene como institución, en la estructura urbana de la ciudad colonial, se ve complejizada y transformada por la dimensión plural que evidencian las nuevas instituciones del Estado en esa misma estructura. De este modo, el paso de la ciudad colonial de los conventos a la ciudad republicana de los edificios públicos sería, en estricto rigor, un cambio cultural y social que se manifiesta espacialmente en la arquitectura, ciudad y paisaje. Las cartografías de Frezier, Sobreviela y Gay, así lo confirman.

En efecto, el cambio de un sistema político a otro, como señala Serrano, "donde la religión dejó de ser el eje estructurante de la sociedad" (Serrano, 2008), fue clave en la transformación de la ciudad colonial organizada en torno al culto público en los conventos e iglesias, a una ciudad de edificaciones y espacios públicos en torno a las calles y avenidas. Con la Colonia la Iglesia ocupa una posición central y jerárquica que se manifiesta territorialmente en sus diferentes localizaciones y en las posiciones de control de la cuadrícula, al punto que estas mismas 
edificaciones y piezas de tejido conventual son los espacios públicos (Figura No 10).

Con el proceso de secularización, la posición de la Iglesia cambia, y según Serrano, también se seculariza y se inserta en la sociedad civil, redefiniendo su rol en la ciudad. Desde una perspectiva espacial, es posible observar que tanto la Iglesia como el Estado inician una nueva relación dentro de la trama y en especial con las calles, mientras la primera se contrae y mimetiza con el estilo neoclásico republicano, las nuevas instituciones estatales adquieren mayor presencia en la ciudad.

Como hemos intentado presentar, los desarrollos y transformaciones de la ciudad de Santiago a lo largo del tiempo, y en particular, lo acaecido en los últimos tres siglos de su historia urbana, han sido posibles dada la gran capacidad de adaptación morfológica y funcional que, desde sus inicios, ha registrado el orden de la cuadrícula. La observación detallada de las diversas cartografías que se suceden permite reflejar el concepto de "vibración" de la trama urbana en el tiempo.

Es en la manzana, la unidad de relleno, donde se establecen las divisiones prediales, usos y condiciones de construcción interior y por tanto donde se registran los procesos de contracción y expansión de las instituciones según el predominio de un sistema político u otro. Y son las calles, las vías que separan a estas unidades de relleno, las que permiten generar no solo el sistema de movimiento de la organización general y su conexión con el territorio, sino los elementos que fijan y determinan los límites entre lo público y lo privado a partir de las líneas de fachada y el sistema de cierre de las edificaciones que se modifican en el tiempo.

Debemos admitir al llegar a este punto, que además la realidad geográfica y topográfica sobre la cual se asienta la cuadrícula en el territorio, le confiere a cada uno de los puntos geométricos con los cuales se trazan las manzanas y calles, una cierta singularidad, que tiene consecuencias en la morfología urbana y tipologías edificatorias. En este marco, la pendiente de Santiago y la lógica de los cursos de agua no son indiferentes.
Desde una perspectiva de conjunto, la vibración de límites en el tiempo entre manzanas y calles, definen un orden que revela muchas combinaciones diferentes estableciendo una trama que está en permanente regularización. Podríamos afirmar que este hecho es sumamente importante, puesto que nos permite ver la realidad de un orden, como el aplicado en la fundación con la planta ortogonal y la superposición del tejido conventual como una primera fase de configuración urbana que no es regular. Las calles cerradas que observamos en "la ciudad de los conventos" interrumpen la continuidad de la trama ortogonal e introducen una modulación distinta de la métrica colonial. El posterior proceso de apertura de calles y la creación de nuevos espacios públicos que rectifican el orden de la cuadrícula surgen, tanto como consecuencia de los cambios de alineación y los movimientos de propiedades como de una nueva manera de comprender la ciudad.

En efecto, como hemos intentado exponer, el trazado de la cuadrícula en el territorio no es un dibujo, sino la concreción de un sistema de fronteras que normalmente se desplazan en el espacio, constituyendo, más que un límite estable, una zona intermedia, de intercambio entre lo público y lo privado, y también entre el exterior público y los interiores públicos.

De modo que la planta de la ciudad funciona como un conjunto normado por disposiciones generales de parcelación, edificación y urbanización, donde cada manzana y calles que la delimitan, responden a las particularidades de su localización, programas, propietarios y pluralidad de operaciones que en ella intervienen. Esta singularidad, a nuestro juicio, posibilita que la lectura de la ciudad se nos revele como una coreografía de movimientos permanentes y por ello, se reconocen distintos modelos de ciudad.

Como si se tratara de distintas tramas, la estructura urbana registra un proceso de transformación del trazado de calles y manzanas que se manifiesta en la geometría y dimensión de las parcelas, composición de las edificaciones, apertura de las calles y espacios públicos. Al observar las tres reconstrucciones del manzanero central de la ciudad se registra un proceso de relleno de la 
trama original propuesta; con un inicio muy hermético y cerrado en relación al trazado de las calles, que se completa con edificaciones de tipología de casas patio, alcanzando su punto máximo en 1910, desde donde comienza un proceso paulatino de apertura de interiores y de comunicación entre lo público y lo privado.

Además debemos considerar aquellas fronteras que mutan debido a una permanente adaptación o vibración entre la línea de fachada o cierre, y la calle, debido a diferentes operaciones de alineación o rectificación de los frentes por ensanche o regularización de los trazados viarios. Esta mínima variación registrada entre los límites públicos y edificaciones privadas, genera un movimiento que permite a su vez abrir interiores y atravesar las manzanas, cuestión de la que no quedan eximidas las manzanas religiosas.

Estos aspectos nos advierten que la realidad de este orden urbano, ha estado en permanente fricción con las condiciones del lugar, e independiente de su estricta racionalidad y supuesta monotonía e igualdad, ha sido bastante sensible a las particulares dimensiones de la parcela, relieve, orientación y otros aspectos como el programa o la función, permitiendo así una variedad de formas urbanas. En efecto, si volvemos a la "ciudad de los conventos" que se formaliza en el siglo XVIII, y que en el último período colonial, en el contexto aún incipiente de la ciudad republicana que emerge con la Independencia del país y secularización del Estado, veremos que la construcción de la ciudad registra la existencia de diversos edificios y espacios públicos que conviven con las edificaciones religiosas.

Es más, la importante presencia de estas no disminuye, por el contrario, aumenta, como queda plenamente confirmado en el Plano de Mostardi Fioretti de 1864, en que las congregaciones religiosas pasan de 38 a 53 instituciones, y conforman parte significativa del tejido urbano y de la expresión pública de una ciudad configurada por la fuerte presencia de nuevos edificios públicos, avenidas, calles, plazas y monumentos. La evidencia que nos entrega esta cartografía, es de suma importancia. Confirma la tesis de Sol Serrano sobre la pervivencia y fortaleza de la religión en Chile y su reorganización e instalación en la sociedad civil. Y también, a nuestro juicio, revela un nuevo modelo de actuación estratégica de la Iglesia y órdenes religiosas en la ciudad y en el territorio.

De este modo, Santiago tomará cuerpo y forma moderna, justamente en la flexibilidad que el parcelario tiene para adaptarse a dife-

Figura $\mathrm{N}^{\circ} 10$

Reconstrucción Situación 1710

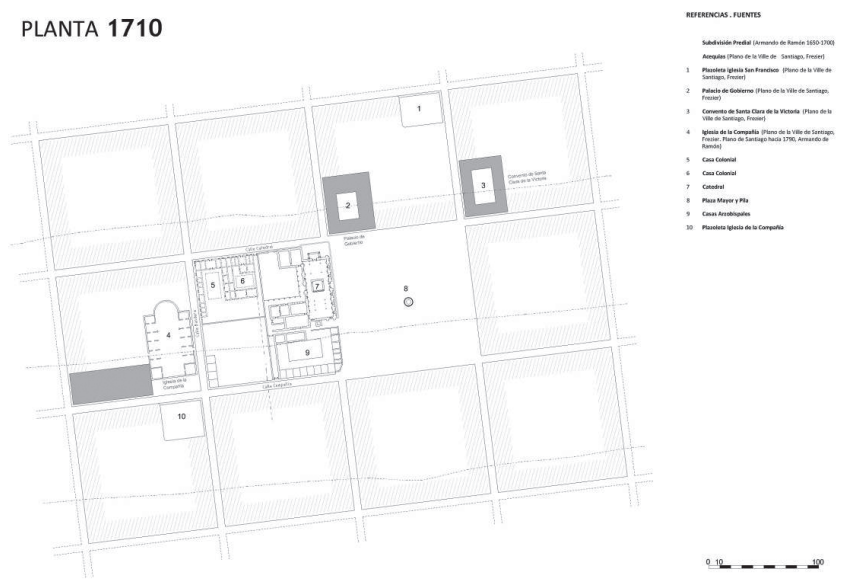

Fuente: Elaboración propia. 
DE la CIUDAD CERRADA DE lOS CONVENTOS A LA CIUDAD ABIERTA DE LOS

rentes tipologías y a la capacidad para acoger distintos programas y poderes que la manzana y la calle registra desde sus orígenes. Y que en el caso de las instituciones religiosas, tuvo a favor, una privilegiada localización dentro de la trama, así como unas dimensio- nes de solares y fachadas que posibilitó, no solo transformaciones prediales, sino variaciones en el tratamiento de la imagen urbana.

En efecto, como podemos observar al comparar las plantas de 1810 y 1910 (Figu-

Figura $\mathrm{N}^{\circ} 11$

Reconstrucción Situación 1810

PLANTA 1810

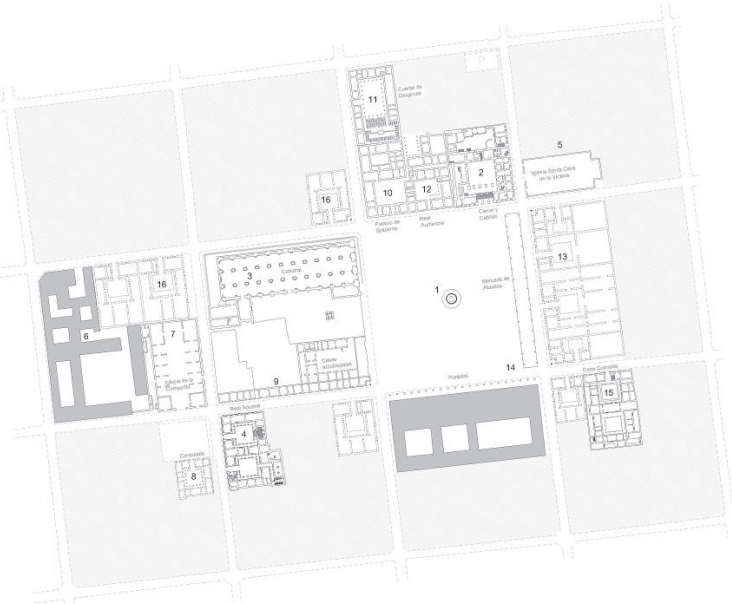

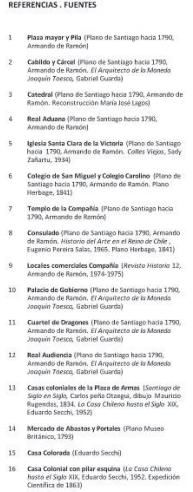

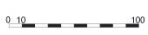

Fuente: Rosas y Pérez, 2010.

Figura $\mathrm{N}^{\circ} 12$

Reconstrucción Situación 1910.

\section{Planta 1910}

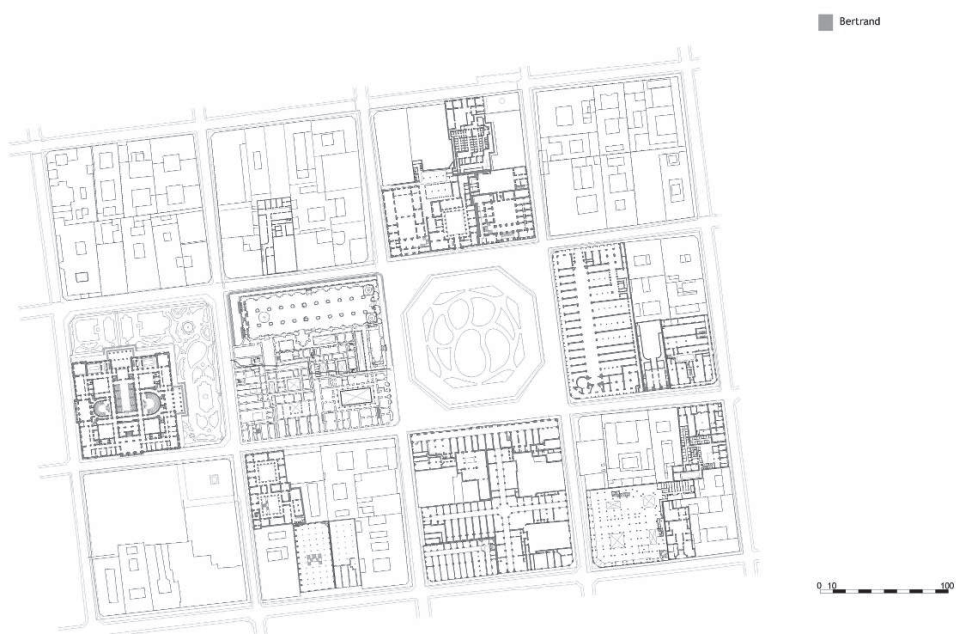

Fuente: Rosas y Pérez, 2010. 
ra $\mathrm{N}^{\circ} 11$ y Figura $\mathrm{N}^{\circ} 12$ ), período en que el manzanero fundacional manifiesta un significativo cambio: "se confirma que uno de los aspectos que queda plenamente ratificado son los esfuerzos registrados en la manzana de la Catedral por modificar la estructura urbana y la voluntad de adquirir una morfología diferente" (Rosas y Pérez, 2010). Es más, los cambios compositivos y estilísticos en el conjunto catedralicio no minimizan la presencia de la institución religiosa, sino por el contrario, la dotan de mayor presencia y competencia con los poderes públicos. El giro del edificio y el tratamiento unitario y representativo del frente principal al espacio público de la Plaza, constituye un hecho urbano y arquitectónico que la ciudad colonial no tenía. Pero parece indudable que la construcción de la nueva Catedral capitalizó las ventajosas condiciones de su localización originaria y dimensión de un gran frente a la Plaza de Armas, y se sumó a la reorganización urbana propiciada por el Estado, que aplicó el repertorio neoclásico en las fachadas de las nuevas instituciones y edificaciones públicas.

La institución de la Iglesia, tanto en la Catedral como en otras edificaciones religiosas, abandona el orden urbano colonial, quedando adscrita definitivamente a la lógica formal y representativa que el nuevo sistema político introduce en la ciudad. Esta reforma del conjunto catedralicio, sin lugar a dudas, es una clara voluntad de dar una nueva imagen de la institución religiosa, pero al mismo tiempo, un afianzamiento del poder de la Iglesia frente a otros poderes principales del Estado y una cierta equivalencia de su representatividad en el conjunto plural de representaciones de la sociedad civil. Entre el período colonial y el republicano, la organización urbana no solo transita desde una ciudad cerrada de los conventos a una ciudad abierta de los espacios públicos, sino la propia Iglesia y las diversas edificaciones religiosas, darán lugar a una serie de transformaciones en las diferentes manzanas y calles a las cuales están adscritas que le otorgarán riqueza formal a la ciudad moderna.

\section{Referencias bibliográficas}

AA.VV. La Ciudad Hispanoamericana. El Sueño de un Orden. Madrid: CEHOPU, 1989.
ALIATA, F. La ciudad regular. Arquitectura, programas e instituciones en el Buenos Aires posrevolucionario, 1821-1835. Buenos Aires: Universidad Nacional de Quilmes, 2006.

DE RAMÓN, A. Santiago de Chile. (15411991). Santiago de Chile: Editorial Sudamericana, 2000.

EDNEY, H. Putting Cartography into the History of Cartography: Arthur H. Robinson, David Woodward, and the Creation of a Discipline. Cartographic Perspectives, 2005, Nº 51, p. $14-29$

GORELIK, A. La grilla y el parque. Espacio público y cultura urbana en Buenos Aires, 1887-1936. Buenos Aires: Universidad Nacional de Quilmes, 2004.

GUARDA, G. La ciudad chilena del siglo XVIII. Buenos Aires: Centro Ed. de América Latina, 1968.

GUARDA, G. Santo Tomás de Aquino y las fuentes del urbanismo indiano. Santiago de Chile: Pontificia Universidad Católica de Chile, 1965.

HARVEY, D. Espacios del Capital. Hacia una Geografía Crítica. Madrid: Editorial Akal, 2007.

HARLEY, B. La nueva naturaleza de los mapas: ensayos sobre la historia de la cartografía. México: Fondo de Cultura Económica, 2005.

HIDALGO, G.; ROSAS, J. y STRABUC$\mathrm{CHI}$ W. La representación cartográfica como producción de conocimiento: Reflexiones técnicas en torno a la construcción del plano de Santiago de 1910. $A R Q, 2012, \mathrm{~N}^{\circ} 80, \mathrm{p}$. 62-75.

MARTÍNEZ, R. La ciudad: (origen - desarrollo - destino) desarrollo urbano de Santiago, 1541-1941. Santiago de Chile: s.n., 1977.

MARTínEZ, R. Santiago de Chile. Los planos de su historia. Siglos XVI al XX. De Aldea a Metrópolis. Santiago de Chile: Publicado por la I.M. de Santiago, 2007.

PEÑA OTAEGUI, C. Santiago de siglo en sig/o. Santiago de Chile: Editorial Zig-Zag, 1944. 
PÉREZ O.F. y ROSAS, J. Portraying and Planning a city. In: DYN, J. \& OFFEN, K. (editores). Mapping Latin America, a Cartographic Reader. Chicago: The University of Chicago Press, 2011.

ROMERO, J. Latinoamérica. Las ciudades y las ideas Siglo XXI. Buenos Aires: Editores Argentina, 2004.

ROSAS, J. y PÉREZ E. La Manzana de la Catedral en el desarrollo de la ciudad de Santiago: dialéctica entre norma formal y episodio notable. Revista 180, 2010, No 26 , p. 16-21.

SÁNCHEZ GAETE, M. Historia de la iglesia en Chile. Santiago de Chile: Editorial Universitaria, 2009-2010.

SCHLÖGEL, K. En el espacio leemos el tiempo. Sobre historia de la civilización y geopolítica. Madrid: Ediciones Siruela, 2007.

SERRANO, S. ¿Qué hacer con Dios en la República? Política y secularización en Chile (1845-1885). Santiago de Chile: Fondo de Cultura Económica, 2008.

SLOTERDIJK, P. En el mundo interior del capital. Para una teoría filosófica de la globalización. Madrid: Biblioteca de Ensayo Siruela, 2007.

THAYER OJEDA, T. Libro oficial del $4^{\circ}$ Centenario de Santiago. Santiago de Chile: Talleres Artuffo, 1941.
THAYER OJEDA, T. Santiago durante el siglo XVI: Constitución de la propiedad urbana y noticias biográficas de sus primeros pobladores. Santiago de Chile: Imprenta Cervantes, 1905.

VALDÉS, I. ¿Obstáculos o factor de desarrollo? Rol de los conventos en desarrollo de tejido urbano. En: ANSART, S. Arquitectura y cultura en el Santiago de Ansart Santiago. Santiago de Chile: Pontificia Universidad Católica de Chile, Escuela de Arquitectura, 2002.

VARGAS LLOSA, M. La Civilización del espectáculo. Madrid: Editorial Alfaguara. 2012.

VICUÑA MACKENNA, B. La transformación de Santiago: notas e indicaciones respetuosamente sometidas a la llustre Municipalidad, al Supremo Gobierno y al Congreso Nacional por el Intendente de Santiago. Santiago de Chile: Imprenta de la Librería del Mercurio, 1872.

VILA, W. El Matadero Municipal y su influencia en el desarrollo urbano de la zona sur de Santiago. Dinámicas de expansión urbana vistas a través de la representación cartográfica. 1875 - 1910. Santiago de Chile: Curso Cartografía e Investigación, 2010. 
